\title{
What are the traits of a social-ecological system: towards a framework in support of urban sustainability
}

\author{
Erik Andersson (iD ${ }^{1,2 凶}$, Dagmar Haase ${ }^{3,4}$, Pippin Anderson ${ }^{5}$, Chiara Cortinovis (D) $^{6}$, Julie Goodness ${ }^{1,7}$, Dave Kendal (iD $^{8}$, \\ Angela Lausch (D) $^{3,4}$, Timon McPhearson (iD) ${ }^{1,9,10}$, Daria Sikorska iD $^{11}$ and Thilo Wellmann (iD ${ }^{3,4}$
}

To ensure that cities and urban ecosystems support human wellbeing and overall quality of life we need conceptual frameworks that can connect different scientific disciplines as well as research and practice. In this perspective, we explore the potential of a traits framework for understanding social-ecological patterns, dynamics, interactions, and tipping points in complex urban systems. To do so, we discuss what kind of framing, and what research, that would allow traits to (1) link the sensitivity of a given environmental entity to different globally relevant pressures, such as land conversion or climate change to its social-ecological consequences; (2) connect to human appraisal and diverse bio-cultural sense-making through the different cues and characteristics people use to detect change or articulate value narratives, and (3) examine how and under what conditions this new approach may trigger, inform, and support decision making in land/resources management at different scales.

npj Urban Sustainability (2021)1:14; https://doi.org/10.1038/s42949-020-00008-4

\section{TRAITS AS SOCIAL-ECOLOGICAL BOUNDARY OBJECTS FOR URBAN STUDIES AND GOVERNANCE}

Traits are attributes that speak to biophysical limitations, pressure on species, ecological functionality, and interactions. They have found their way to the forefront of many discussions and debates about ecosystem dynamics and, with a slight time lag, socialecological systems ${ }^{1-3}$. The promise is that a traits framework can further our understanding of patterns, dynamics, interactions, and tipping points within and across complex social-ecological systems. But what will it take to make good on this promise, in particular for our cities, where change is fast and-being the places where the majority of humans live-human perceptions are particularly diverse? What kind of framing, what research, would allow traits-classically understood as a different representation and interpretation of well-established and known properties of the social-ecological system — to fully work as "mediators" for understanding the behavior, functions, and needs of urban systems under pressure?

This perspective aims to contribute to the current wide-ranging discussion about traits in both theoretical and applied ecology, and parallel work on better understanding human connections to nature. To this end, we explore the potential of using an expanded conceptualization of traits as a platform for integrated approaches to understanding the different facets of people-in-nature relationships and dynamics ${ }^{4,5}$.

Expanding from the original "characteristics which have demonstrable links to the organism's function" ${ }^{\prime \prime}$, we see traits as a nexus where different theories and conceptualisations about social-ecological systems can connect, intertwine and comprehensively allow us to assess the current state of a system-and even more importantly, evaluate the implications of change (Box 1 and Fig. 1). To make it an integrative and useful framework for urban studies and policy/practice, traits need to be easy to recognise and relevant to decision makers across scales and in different contexts. In addition, information on trait profilesgeneric as well as site specific - need to be easily available through monitoring or in databases.

Our argument is threefold: The first dimension focuses on how to assess and anticipate change by establishing chains of interconnected traits that describe and causally connect sensitivity and response to different urban pressures such as heat, soil compaction, environmental toxicants, and stormwater runoff, understood through "response" traits $^{7-10}$ to their functional consequences ${ }^{11}$, mediated by "effect traits". The second dimension is grounded in human perceptions and appraisal of diversity to highlight the different cues and characteristics people use to detect change or articulate value narratives, and it is linked to the role of traits in ecological literacy. Here, we propose traits be viewed as boundary objects, i.e., features that carry meaning across society (although the meanings might be diverse and sometimes conflicting), and that this second dimension is essential for understanding the role of society and humans in a traits framework. The third dimension outlines how the first two dimensions connect to inform and support decision making and management at different scales, for example in different, multilayer, and multiactor governance processes ${ }^{12}$ (Fig. 2).

\section{The first dimension: response and its effect outcomes}

Trait-based approaches have been used for descriptive purposes ${ }^{13}$ to enable broader global comparisons that transcend the constraints of regional taxonomic diversity (e.g., see refs. ${ }^{6,14}$ )

\footnotetext{
${ }^{1}$ Stockholm Resilience Centre, Stockholm University, Kräftriket 2b, 10691 Stockholm, Sweden. ${ }^{2}$ Unit for Environmental Sciences, North-West University, Private Bag X6001, Potchefstroom 2520, South Africa. ${ }^{3}$ Geography Department, Humboldt University Berlin, Unter den Linden 6, 10099 Berlin, Germany. ${ }^{4}$ Department Computational Landscape Ecology, Helmholtz Centre for Environmental Research-UFZ, Permoserstr. 15, 04318 Leipzig, Germany. ${ }^{5}$ Department of Environmental and Geographical Science, University of Cape Town, RondeboschPrivate Bag X3, Cape Town 7701, South Africa. ${ }^{6}$ Centre for Environmental and Climate Research, Lund University, Sölvegatan 37, 22362 Lund, Sweden. ${ }^{7}$ Global Risk Governance Programme, Department of Public Law, Law Faculty, University of Cape Town, RondeboschPrivate Bag X3, Cape Town 7701, South Africa. ${ }^{8}$ School of Technology, Environments and Design, University of Tasmania, Private Bag 78, Hobart, TAS 7001, Australia. ${ }^{9}$ Urban Systems Lab, The New School, 79 Fifth Avenue, 16th Fl., New York, NY 10003, USA. ${ }^{10}$ Cary Institute of Ecosystem Studies, Box AB; 2801 Sharon Turnpike, Millbrook, New York 12545, USA. ${ }^{11}$ Institute of Environmental Engineering, Department

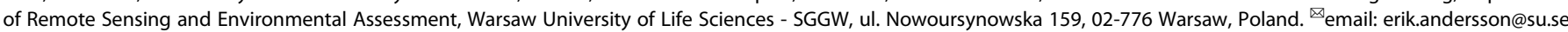


and allow for the types of generalizations sought in ecology ${ }^{15,16}$. Traits offer a way of looking at causality and change, and trait profiles can indicate whether emergent communities are functionally different from historic communities. To this end, traits can be divided into those that determine an organism's sensitivity and response to environmental factors, and those that relate to its effect on the environment ${ }^{4,17}$. When combined, the two categories of traits can be used to detect, identify and monitor the current state of ecosystems, and to anticipate the outcomes of change ${ }^{8,10,17-19}$.

An environment described through traits: The urban biophysical environment includes hydrology and soils, as well as biotic elements (flora and fauna), and understanding the relationships among those components is necessary to measure and anticipate the profound effects of urbanisation. Currently, knowledge of plant traits is most developed ${ }^{4,20}$, although there is work emerging on traits for animals or other taxonomic groups $s^{8,21}$ as well as for soil and geodiversity ${ }^{22}$. Animal studies so far tend to

\section{Box 1 definitions}

Functional trait: A feature of an organism which has demonstrable links to the organism's function ${ }^{69}$, and, as such, "determines the organism's response to pressures (response trait), and/or its effects on ecosystem processes or services (effect trait). In plants, functional traits include morphological, ecophysiological, biochemical and regeneration traits, including demographic traits (at population level). In animals, these traits are combined with life history and behavioral traits (e.g., guilds, organisms that use similar resources/habitats) ${ }^{\prime \prime 70}$, p. 2779. Boundary object: "[...] those [...] objects which both inhabit several intersecting social worlds and satisfy the information requirements of each of them. Boundary objects are objects, which are both plastic enough to adapt to local needs and the constraints of the several parties involving them, yet robust enough to maintain a common identity across sites. [...] They have different meanings in different social worlds [and across cultures] but their structure is common enough to more than one world to make them recognizable, a means of translation." ${ }^{71}$ p. 393 , see also ${ }^{72}$.

Social-ecological traits (expanded definition): An ecologically or socially (inter) active and demonstrable feature of the environment at any level or scale. A social-ecological trait either mediates reactions to selective social-ecological filtering (response trait) or determines effects on ecosystem processes or services (effect trait), or both. The aggregate trait profile of a given entity should ideally speak both to ecological functioning and socio-cultural meaning. focus on habitat modelling for birds, insects, invertebrates and a few on mammals (e.g., see refs. ${ }^{3,8,16,23}$ ). Many studies have looked at the impact of different community assemblages on ecological functions through effect traits and, in particular, how altered or dynamically changing communities will affect ecosystem process through changes in representation of effect traits (but e.g., see ref. ${ }^{23}$ ). However, the link between traits and ecosystem functions has largely been inferred (ibid.), and is, according to Cadotte et al. $^{24}$, rudimentary (see also ${ }^{25}$ and $^{26}$ ). As we indicated with our definition of traits (Box 1), we see a value in including soil properties as traits and not to leave them as "environmental filters", as this may offer a more dynamic way of understanding one of the major urban processes of change-soil sealing and compaction-and thus help guide urban development.

Traits at different levels and scales: Traits at the species level are by far the best known and most explored, but there are also studies that use traits from other ecological levels-gene, community, ecosystem and landscape-as indicators for tracking response to stress ${ }^{27}$ and calculating functional "performance". A common approach to scale is to aggregate species level information. For example, the average values of aggregations of plant species traits at the ecosystem level provide a basis for calculating overall sensitivity to pressures ${ }^{28}$. This in turn, and drawing on different sets of traits, allows for estimations of changes in ecosystem function (e.g., see ref. ${ }^{29}$ ). However, there are other characteristics that could also be understood as traits. At the landscape level the mosaic of ecosystems and the location and combination of patches are used to assess flows and exchange across larger areas (e.g., see ref. ${ }^{30}$ ). A good example is a city in a river valley, where water flows and exact location within the drainage basin affect urban green spaces and their aggregated matter production, $\mathrm{CO}_{2}$ absorption or carbon subsection $^{31}$. Aggregate, or higher-level traits, such as structural composition and functional diversity of vegetation, matter flows, or species migration, are the most common traits analysed through remote sensing in order to track trends ${ }^{25}$. More work needs to be done to explore relevant traits at different levels of organisation to match the scale and nature of disturbances and the spatial and temporal scale at which different functions are

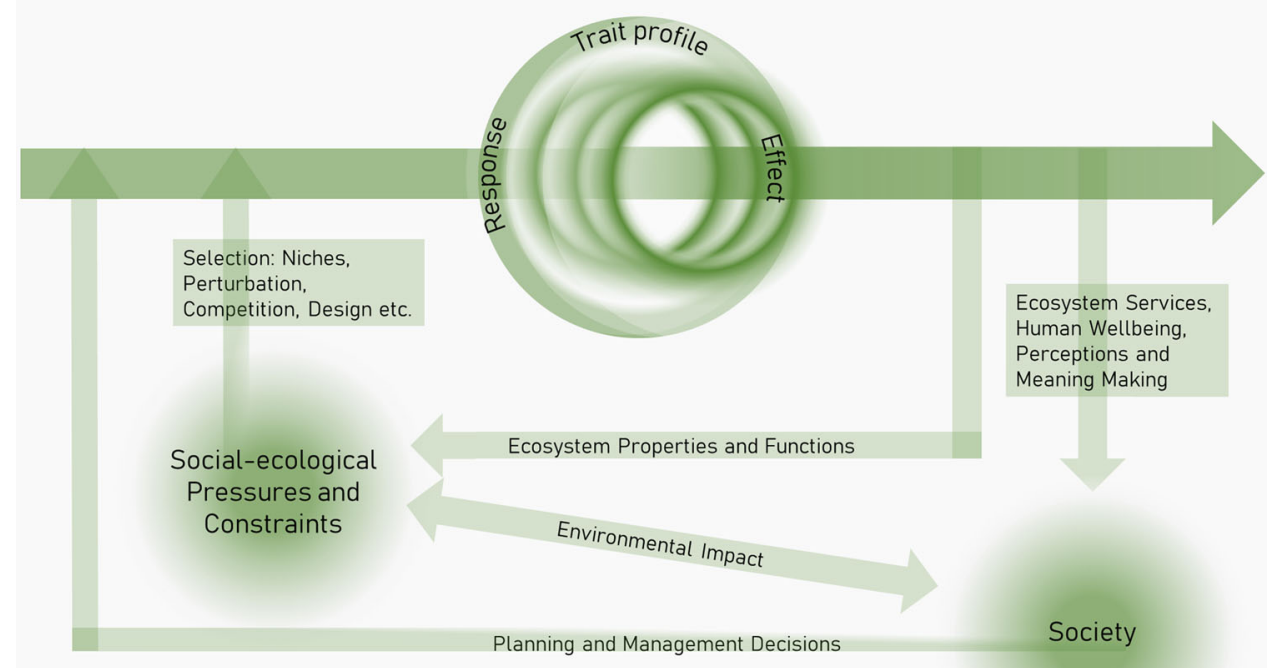

Fig. 1 Traits within social ecological systems. Theoretical flow chart linking the entities of a social-ecological system to its traits, demonstrating how a traits framework-as outlined in this article-might be positioned to support the analysis, interpretation and governance of urban systems. 


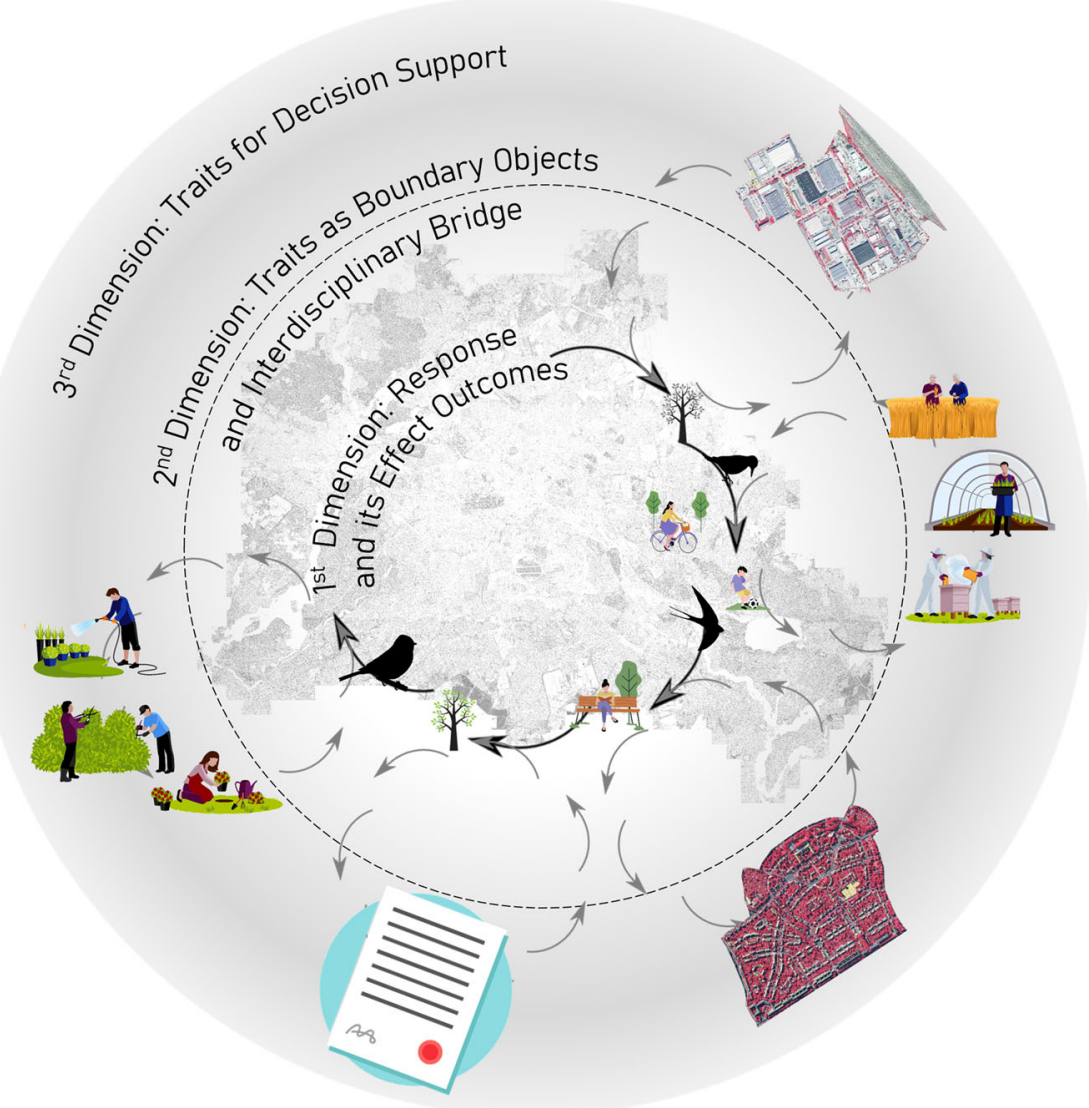

Fig. 2 A traits framework for scientific study and practical application. The three dimensions of a social-ecological traits framework for understanding and governing urban systems. The first dimension is represented by observable traits of the urban environment, e.g., features of humans and other co-inhabiting species and their differing responses to pressures and selection, leading to functional consequences and finally, altered characters of an urban social-ecological system. The second dimension is characterized by feedback loops between those effect outcomes and individual and collective perceptions and decision making. Lastly, the third dimension is represented by urban ecosystem planning and management embedded in governance processes and instruments. Through its ability to connect different spheres and discourses, an expanded traits framework can aim for effective and inclusive decision support that is responsive and place-adapted. By expanding and bridging these three dimensions, we can connect different insights and knowledge about ecosystem function and human perceptions, values and interactions with the environment. This will support the development of a (meta-) theoretically grounded, practically applicable traits framework to interrogate reciprocal feedback linkages and nature-human relationships. The figure includes resources from Freepik.com.

most relevant. Being explicit about scale, and ensuring traits at different levels are nested, allows for tracking of processes across scales.

Individual traits, trait combinations, and interlinked suites of traits: A key promise of traits is to provide mechanistic explanations of observed structure, patterns and functionality, which is usually demonstrated through statistical correlations. Further developing suites of response and effect traits could provide valuable input and indicators for assessment and monitoring frameworks. For example, traits could inform DPSIR (drivers, pressures, state, impact, and response) models by anticipating or measuring response to a pressure and the direct and indirect impact this response could have. At a more fundamental level, traits explain whether impacts may be causing a change in the functional state of the system. Interlinked traits, from those determining sensitivity, to those mediating response elicited by sensitivity, could improve mechanistic understanding by supporting the development of stepwise response-effect pathways ${ }^{17}$. For example, land conversion-like the soil sealing and compaction typical in cities-fundamentally alters soil properties, which in turn affects vegetation. Soil properties influence the growth and composition of plant communities. This translates into trait-mediated effects like reduction of total leaf area, which leads to cascading effects of early leaf senescence and limitation of stomatal transpiration. This reduces water exchange capacity, which in turn is key for mediating air cooling or shading and other functions/services plants may offer to humans.

For this first dimension, trait databases, classical field inventories, and experiments, remote sensing data, and GIS-based information are crucial ${ }^{15,32}$. We see valuable developments from the past two decades of research towards achieving a traits response-effect library in both the ecology and remote sensing communities ${ }^{33,34}$, even if recent advances from remote sensing studies still rarely find entrance into urban planners' work and policy decision-making ${ }^{35}$. In particular, the development in the technical dimensions of detecting traits and trait variation ${ }^{20,34}$ and tracking these over time, has recently rapidly developed. The progress in application of high-resolution hyperspectral data, light detection, and ranging (LiDAR) or the possibility of mounting the recently developed sensors on unmanned aerial vehicles (UAVs) equip the researchers with addditional tools that can not only expand the range of measurable traits but also allow easy access to data. This provides a powerful support for urban planning and, ultimately, urban governance. Moreover, applications for tablets or smartphones offer alternative ways to directly involve 
citizens in ecosystem monitoring and further develop citizen science (e.g., see refs. ${ }^{22,36}$ ).

\section{The second dimension: traits as an interdisciplinary bridge}

The literature explicitly using the term traits tends to focus on soil, geodiversity, plant, and community trait profiles as an outcome of social-ecological selection through environmental conditions, species interactions, human preferences, management regimes etc. (e.g., see refs. ${ }^{4,37}$ ). This approach has started to address not just how people filter traits (e.g., see ref. ${ }^{38}$ ), but the reason(s) behind either individual or group decisions that lead to filtering (e.g., see refs. ${ }^{39,40}$ ). Here, we propose that the environment, described through traits, could be considered a boundary object (Box 1), allowing for a multiplicity of views, disciplinary connections, engagements, and perceptions, and that speaks to the complexity of social-ecological systems. This will expand the range of functions used to describe a system, and the types of traits required to capture them.

Ecological functions relative to ecosystem services: The plant and animal traits that people respond to may not be the same ones that mediate responses to environmental change. For example, seed mass and specific leaf area are important plant functional traits ${ }^{41}$ but are less likely to influence people's preferences for urban vegetation (e.g., see ref. ${ }^{42}$ ). Indeed, some esthetic traits promoted by human decision-making and management, such as selection for leaf variation and predominantly deciduous plants, may also lead to the predominance of woody plants that are strongly affected by water stress, fungal attack or insect infestation or trimmed canopies, and thus promote reduced fitness of individual organisms and communities ${ }^{43}$. On the other hand, a successful reproductive strategy such as the emission of high quantities of pollen might limit the suitability to humandominated environments (including cities) due to allergenic potential ${ }^{44}$. Do we need more, or different traits to link ecosystem dynamics more strongly to the lived reality of people? Are traits too simplistic proxies, or perhaps too specific features, to express and understand people-nature interactions? Introducing humans and human appraisal into our trait framework encourages a broader definition of what might be relevant traits. Traits used in this way provide a specific link to interactions and feedback mechanisms between human wellbeing and functional ecology (and respective proxies that serve multiple relational (feedback) purposes).

Traits as relational features: Trait lists already include features which are easy to understand and readily detected by human sensory organs, and thus find traction in society or connect to existing ethno-biological narrations ${ }^{39}$. Traits such as flower colour, leaf shape, and canopy density, which may not necessarily be considered central functional traits, are important drivers of people's preferences $37,39,45,46$. Both size and colour of the flowers are plant traits affecting people's perception ${ }^{47}$ and can thus be an important factor for gaining societal approval for more urban greenery ${ }^{48}$. Seasonality is another relevant trait; for example, an extended flowering season ${ }^{49}$. At the same time, there is a growing interest in flowers and blooming meadows among gardeners worldwide also to support insects in urban landscapes to counteract global biodiversity decline 37,39 .

In this vein, we argue that traits are a formative force influencing human wellbeing and world views, giving shape to ecological systems and linked human affordances (through, e.g., shade and sensory stimuli), and social systems by shaping the context of human activities and experiences. For example, we know that people recognize and value a wide range of plant traits, and that this has even been identified as a useful way to speak about the state of nature and large scale change ${ }^{50}$. There is evidently a role for traits and trait composition as language for more "functional" ecological literacy ${ }^{36,50}$. This position as a boundary object needs to be further explored and linked to the responses of social-ecological urban systems, which are subject to a multitude of pressures, including climate change and soil sealing.

Traits as boundary objects and connectors between knowledge systems: What is needed to better position and connect the concept of traits to multiple different literatures and disciplines and enable traits to be used as a useful boundary object? Many disciplines outside the ecological and environmental sciences have an interest in understanding ecosystem function and biodiversity, and how people relate to these ideas. Traits, and deeper meanings of some traits, can be found within environmental psychology, ethno-botany/zoology and environmental anthropology. Trait-based approaches may also be well suited to engage with other ways of knowing, such as traditional ecological knowledge and religious systems. This disciplinary and transdisciplinary knowledge is needed if traits are to connect socialecological attributes to diverse human values and wellbeing dimensions, and to ensure we do not produce trivial and culturally biased conclusions ${ }^{51,52}$. Based on the diverse use and potential meanings of the word "traits", we argue that a traits framework, and traits-focused interdisciplinary discussions and projects, could support a dual ontological stance where some connections are more universal, while others are inherently interpretational or simply individual. Hence, this may help to effectively connect the social and cultural dimensions of traits to a deep ecological understanding of change and its multiple consequences. This would be an important development that allows for critical engagement with concepts like tipping points and system states and what they actually mean in a complex social-ecological urban system.

\section{The third dimension: traits for decision support}

The major purpose of the traits concept, as we present it here, is to develop an ontologically inclusive traits framework capable of addressing both the resilience of ecological functions and the experiential and relational aspects of human interactions with nature. On the applied side, this would be relevant to a wide range of decision-making processes, not least urban planning. Clearly visible and easy-to-map traits are well-suited as indicators to describe the state of urban landscapes relevant for biodiversity and society alike. To this end, there are still many questions that need answers. For example, how can the understanding of trait profiles help improve species selection in times of climate change, to inform management priorities and strengthen cross-community stewardship, especially where the diversity of response traits may be low? And which traits are incompatible and how are they best kept separate, a question particularly relevant in the light of zoonosis like the COVID-19 pandemic in 2020? And finally, what traits could best serve as reasonable proxies or indicators to provide either cues or early signals of species responses to (fundamental) change in urban environments?

Supporting holistic decisions: Already now we see increasing use of traits in modelling and decision support tools like CiTree and $i T_{r e} e^{53,54}$. As cities strive to adapt to climate change by, for example, revising tree species selection (e.g., see ref. ${ }^{55}$ ), an improved understanding of the relationship between detectable functional traits and the provision of ecosystem services can help avoid maladaptation ${ }^{56}$. For example, replacing shade trees with fine-foliaged trees may improve adaptation to future climates but would not provide the same levels of climate mitigation ${ }^{57}$. From a decision-making point of view, key traits are those determining the response of ecosystems to human-induced pressures such as air pollution, soil sealing, or urban heat islands, as well as those mediating the effects of these changes on ecosystem services and related benefits as perceived by people ${ }^{8,58}$. 
A traits framework that uses our social-ecological definition of traits might support informed decisions on trade-offs. For example, invasive or non-native plants are often seen as ecologically problematic, but certain traits such as high leaf coverage or flower colour and shape make them socially desirable ${ }^{48}$. Traits connected to more social-ecological dimensions will allow for a more holistic assessment of options and the potential trade-off implications of different choices. While decisions are often grounded, implicitly or explicitly, in considerations of multiple traits (e.g., see ref. ${ }^{53}$ ), we need to ensure that traits considered in the plant selection include both traits related to broad and diverse preferences and desires for ecosystem services and traits, that ensure a resilient response to drivers of change that may impact their ability to provide these services (see, e.g., the scoring system for urban vegetation species proposed by Tiwary et al. ${ }^{59}$ ).
Urban planning informed by an expanded traits framework and spatial-temporal patterns of trait profiles has the promise to be adaptive in the best sense and thus, resilient. More city and regional comparisons are needed to make target setting and threshold discussions grounded and allow for global discussion. This requires a targeted effort at broader inclusion of cases and trait data from different climates, biomes, multiple ecological levels but also cultures, and would move traits studies towards a truly transdisciplinary venture with real impact on how we plan and manage our cities.

Feasible and easy to use: Indicator traits need to be robust, easy to measure and low-cost to assess, and have a causal link to relevant social-ecological processes and patterns (such as ecosystem services for recreation, cooling or food $\left.{ }^{4,60}\right)$. The potential use in planning and decision-making at multiple levels again point to the need to discuss the scales and levels for traits studies to make sure trait levels are nested and logically

Table 1. Research agenda.

\begin{tabular}{|c|c|c|c|}
\hline & Data & Questions & $\begin{array}{c}\text { Urban governance and } \\
\text { practice contexts }\end{array}$ \\
\hline $\begin{array}{l}\text { Traits for } \\
\text { monitoring and } \\
\text { comparison }\end{array}$ & $\begin{array}{l}\text { Remote sensing data on } \\
\text { urban soils and } \\
\text { vegetation, surveys and } \\
\text { inventories, } \\
\text { environmental } \\
\text { monitoring }\end{array}$ & $\begin{array}{l}\text { Heterogeneity within } \\
\text { and across cities, spatial } \\
\text { distribution high/low } \\
\text { trait diversity }\end{array}$ & $\begin{array}{l}\text { Urban growth, land } \\
\text { conversion, restoration, } \\
\text { monitoring changes } \\
\text { induced by urbanization } \\
\text { and climate change }\end{array}$ \\
\hline $\begin{array}{l}\text { Response-effect } \\
\text { chains }\end{array}$ & $\begin{array}{l}\text { Experimental and } \\
\text { longitudinal studies in } \\
\text { different urban settings, } \\
\text { interactions between } \\
\text { soils-vegetation-animals }\end{array}$ & $\begin{array}{l}\text { What are the effect } \\
\text { outcomes (and iterative } \\
\text { loops) of response to } \\
\text { change? What does } \\
\text { response diversity really } \\
\text { mean? }\end{array}$ & $\begin{array}{l}\text { Design of nature-based } \\
\text { solutions, impact } \\
\text { assessment of planning } \\
\text { actions, offset schemes } \\
\text { and compensation } \\
\text { mechanisms }\end{array}$ \\
\hline $\begin{array}{l}\text { Experience and } \\
\text { sense-making of } \\
\text { diversity and } \\
\text { dimensions of } \\
\text { diversity }\end{array}$ & $\begin{array}{l}\text { In-depth value and } \\
\text { preference studies, self- } \\
\text { reported social media, } \\
\text { narratives and } \\
\text { biocultural/ethno- } \\
\text { biological studies }\end{array}$ & $\begin{array}{l}\text { What are the } \\
\text { consequences of human } \\
\text { perceptions, preferences } \\
\text { and dislikes, what are } \\
\text { the ES consequences of } \\
\text { different responses to } \\
\text { pressures? }\end{array}$ & $\begin{array}{l}\text { Ecological literacy, } \\
\text { awareness raising, } \\
\text { citizen science, } \\
\text { participation, } \\
\text { stewardship }\end{array}$ \\
\hline
\end{tabular}

Research agenda for developing and grounding an extended, interdisciplinary and practically applicable traits framework. The research questions are connected and meant to serve as a basis for integration, and management and decision making will benefit from the integrated framework. 
commensurable. Higher-level, larger-scale properties such as landscape morphology and water availability, the profile of pest communities or potential invasions can be further informed by the development of more detailed traits frameworks. This makes traits frameworks highly relevant also from an economic, social and health perspective, especially in intensely managed environments like cities, where combinations of multiple stressors and external factors create small scale heterogeneity and fast temporal change in pressures ${ }^{61,62}$.

Trait selection can play that important role for assisting in the planning and design and then evaluation of the functionality of high-biodiversity green spaces ${ }^{63}$, and for trait-informed assessment of "performance", e.g., of ecologically protected areas. A relevant example to this point is the ongoing debate about how to evaluate ex-ante, and then monitor, the implementation of nature-based solutions ${ }^{62,64}$, which remains a challenge ${ }^{65}$. Could this be done using traits instead of commonly used area-based indicators? Could traits become the basis to design and assess the impacts of offsets and compensation measures, thus increasing their efficacy? From this perspective, we see in a traits framework the potential to support a shift towards more flexible and effective planning approaches, more suitable to address today's urban challenges and to promote greater well-being, sustainability and resilience of present and future cities.

\section{Conclusion and looking ahead}

Through their direct relation to ecosystem services such as cooling and fresh air, easy-to-understand traits can be an entry-point for nature awareness and, subsequently, ecological knowledge in decision-making both at the citizen and the societal level ${ }^{66}$. However, to make traits successful indicators of global, regional, or local environmental changes, it is vital that urban society is understood as diverse across characteristics such as cultural background, physical mobility, gender, age, degree of formal or informal education, access to information and communication, purchasing power, and political influence ${ }^{67}$. All these factors affect the needs, preferences, and values of individuals and groups, and the way each interpret human-nature relationships. Only by taking these factors into account, planning for spatial-temporal diversity in traits across an urban landscape will create more inclusive urban systems that foster multiple benefits for both people and biodiversity ${ }^{68}$.

The expansion and implementation of a traits-based approach for urban systems is impeded by availability of traits data. For example, trait databases are usually a primary data source in studies on urban ecology, however, these data have mainly been collected in natural areas or controlled environments such as laboratories, where organisms may display different trait values than those in urban environments. Studies have also been concentrated in the global north, and there are major challenges with potentially transferring and adapting thinking mostly developed in the Global North to rapidly urbanising areas in Africa, Asia and South America.

To enable a social-ecological traits framework for interdisciplinary discussion and for guiding urban planning and decision making, we suggest a three-pronged approach for building a social-ecological understanding of trait mediated interactions and their implications, and make this understanding useful to practice (Table 1). Large-scale monitoring needs to be coupled with indepth understanding of response mechanisms and their impact on ecosystem functions as well as services, and a deeper connection between traits and human perception as well as sense-making of the world we live in. Application to human perception and sense-making requires more data, theory and empirical work, and especially the way people relate to traits will likely vary considerably across cities and contexts across the globe. All branches of investigation need to be embedded in an interdisciplinary discussion about the role that traits play for social-ecological interactions and mutual exchange. Drawing on this broad evidence base, synthesized knowledge will offer a more comprehensive support for urban decision making, not least in anticipation of future change.

Received: 8 April 2020; Accepted: 28 November 2020; Published online: 25 March 2021

\section{REFERENCES}

1. Díaz, S. et al. Linking functional diversity and social actor strategies in a framework for interdisciplinary analysis of nature's benefits to society. Proc. Natl Acad. Sci. USA 108, 895-902 (2011).

2. Lavorel, $\mathrm{S}$. et al. Using plant functional traits to understand the landscape distribution of multiple ecosystem services. J. Ecol. 99, 135-147 (2011).

3. Vandewalle, M. et al. Functional traits as indicators of biodiversity response to land use changes across ecosystems and organisms. Biodivers. Conserv. 19, 2921-2947 (2010).

4. de Bello, F. et al. Towards an assessment of multiple ecosystem processes and services via functional traits. Biodivers. Conserv. 19, 2873-2893 (2010).

5. McPhearson, T. et al. Advancing urban ecology toward a science of cities. Bioscience 66, 198-212 (2016).

6. Cernansky, R. Boidiversity moves beyond counting species. Nature 546, 22-24 (2017).

7. Elmqvist, T. et al. Response diversity, ecosystem change, and resilience. Front. Ecol. Environ. 1, 488-494 (2003).

8. Hevia, V. et al. Trait-based approaches to analyze links between the drivers of change and ecosystem services: synthesizing existing evidence and future challenges. Ecol. Evol. 7, 831-844 (2017).

9. Sterk, M. et al. Assess ecosystem resilience: linking response and effect traits to environmental variability. Ecol. Indic. 30, 21-27 (2013).

10. Mori, A. S., Furukawa, T. \& Sasaki, T. Response diversity determines the resilience of ecosystems to environmental change. Biol. Rev. 88, 349-364 (2013).

11. Ignatieva, M., Haase, D., Dushkova, D. \& Haase, A. Lawns in cities: from a globalised urban green SPACE phenomenon to sustainable nature-based solutions. Land 9, 73 (2020).

12. Buijs, A. et al. Active citizenship for urban green infrastructure: fostering the diversity and dynamics of citizen contributions through mosaic governance. Curr. Opin. Env. Sust. 22, 1-6 (2016).

13. McDonnell, M. J. \& Hahs, A. K. The future of urban biodiversity research: Moving beyond the 'low-hanging fruit'. Urban Ecosyst. 16, 397-409 (2013).

14. Duncan, R. P. et al. Plant traits and extinction in urban areas: a meta-analysis of 11 cities. Glob. Ecol. Biogeogr. 20, 509-519 (2011).

15. Cornelissen, J. H. C. C. et al. A handbook of protocols for standardised and easy measurement of plant functional traits worldwide. Aust. J. Bot. 51, 335-380 (2003).

16. Blaum, N., Mosner, E., Schwager, M. \& Jeltsch, F. How functional is functional? Ecological groupings in terrestrial animal ecology: towards an animal functional type approach. Biodivers. Conserv. 20, 2333-2345 (2011).

17. Suding, K. N. et al. Scaling environmental change through the community-level: a trait-based response-and-effect framework for plants. Glob. Chang. Biol. 14, 1125-1140 (2008)

18. Chapin, F. S., Torn, M. S. \& Tateno, M. Principles of ecosystem sustainability. Am. Nat. 148, 1016-1037 (1996).

19. Sikorska, D. et al. Variation in leaf surface hydrophobicity of wetland plants: the role of plant traits in water retention. Wetlands 37, 997-1002 (2017).

20. Lausch, A. et al. Linking earth observation and taxonomic, structural and functional biodiversity: local to ecosystem perspectives. Ecol. Indic. 70, 317-339 (2016).

21. Deans, A. R., Yoder, M. J. \& Balhoff, J. P. Time to change how we describe biodiversity. Trends Ecol. Evol. 27, 78-84 (2012).

22. Lausch, A. et al. Linking remote sensing and geodiversity and their traits relevant to biodiversity_Part I: soil characteristics. Remote Sens. 11, 2356 (2019).

23. Luck, G. W., Smallbone, L., Threlfall, C. \& Law, B. Patterns in bat functional guilds across multiple urban centres in south-eastern Australia. Landsc. Ecol. 28, 455-469 (2013).

24. Cadotte, M. W., Carscadden, K. \& Mirotchnick, N. Beyond species: functional diversity and the maintenance of ecological processes and services. J. Appl. Ecol. 48, 1079-1087 (2011).

25. Schneider, F. D. et al. Mapping functional diversity from remotely sensed morphological and physiological forest traits. Nat. Commun. 8, 1-12 (2017).

26. Jetz, W. et al. Monitoring plant functional diversity from space. Nat. Plants 2, 1-5 (2016). 
27. Lausch, A. et al. Understanding and assessing vegetation health by in situ species and remote-sensing approaches. Methods Ecol. Evol. 9, 1799-1809 (2018).

28. von der Lippe, M., Buchholz, S., Hiller, A., Seitz, B. \& Kowarik, I. CityScapeLab Berlin: a research platform for untangling urbanization effects on biodiversity. Sustainability 12, 2565 (2020).

29. Kattge, J. et al. TRY - a global database of plant traits. Glob. Change Biol. 17, 2905-2935 (2011).

30. Bastian, O., Haase, D. \& Grunewald, K. Ecosystem properties, potentials and services-The EPPS conceptual framework and an urban application example. Ecol. Indic. 21, 7-16 (2012).

31. Evers, C. R. et al. The ecosystem services and biodiversity of novel ecosystems: a literature review. Glob. Ecol. Conserv. 13, e00362 (2018).

32. Pérez-Harguindeguy, N. et al. New handbook for stand-ardised measurement of plant functional traits worldwide. Aust. J. Bot. 61, 167-234 (2013).

33. Kissling, W. D. et al. Towards global data products of essential biodiversity variables on species traits. Nat. Ecol. Evol. 2, 1531-1540 (2018).

34. Wellmann, T. et al. Urban land use intensity assessment: the potential of spatiotemporal spectral traits with remote sensing. Ecol. Indic. 85, 190-203 (2018).

35. Wellmann, T. et al. Remote sensing in urban planning: Contributions towards ecologically sound policies? Landsc. Urban Plan. 204, 103921 (2020).

36. llieva, R. T. \& McPhearson, T. Social-media data for urban sustainability. Nat. Sustain. 1, 553-565 (2018).

37. Goodness, J., Andersson, E., Anderson, P. M. L. \& Elmqvist, T. Exploring the links between functional traits and cultural ecosystem services to enhance urban ecosystem management. Ecol. Indic. 70, 597-605 (2016).

38. Williams, N. S. G. et al. A conceptual framework for predicting the effects of urban environments on floras. J. Ecol. 97, 4-9 (2009).

39. Kendal, D., Williams, K. J. H. \& Williams, N. S. G. Plant traits link people's plant preferences to the composition of their gardens. Landsc. Urban Plan. 105, 34-42 (2012).

40. Goodness, J. Urban landscaping choices and people's selection of plant traits in Cape Town, South Africa. Environ. Sci. Policy 85, 182-192 (2018).

41. Westoby, M. A leaf-height-seed (LHS) plant ecology strategy scheme. Plant Soil 199, 213-227 (1998).

42. Avolio, M. L. et al. Understanding preferences for tree attributes: the relative effects of socio-economic and local environmental factors. Urban Ecosyst. 18, 73-86 (2015).

43. Wilson, A., Kendal, D. \& Moore, J. L. Humans and ornamental plants: a mutualism? Ecopsychology 8, 257-263 (2016).

44. Jochner-Oette, S., Stitz, T., Jetschni, J. \& Cariñanos, P. The influence of individualspecific plant parameters and species composition on the allergenic potential of urban green spaces. Forests 9, 284 (2018).

45. Kendal, D. et al. Quantifying plant colour and colour difference as perceived by humans using digital images. PLoS One 8, e72296 (2013).

46. Kütt, L. et al. Multi-user quality of floral services along a gradient of margin habitats between semi-natural grasslands and forests. Appl. Veg. Sci. 21, 363-372 (2018).

47. Hoyle, H., Hitchmough, J. \& Jorgensen, A. All about the 'wow factor'? The relationships between aesthetics, restorative effect and perceived biodiversity in designed urban planting. Landsc. Urban Plan. 164, 109-123 (2017).

48. Sikorski, P. et al. Low-maintenance green tram tracks as a socially acceptable solution to greening a city. Urban For. Urban Gree. 35, 148-164 (2018).

49. Andersson, E., Barthel, S. \& Ahrné, K. Measuring social-ecological dynamics behind the generation of ecosystem services. Ecol. Appl. 17, 1267-1278 (2007).

50. Püffel, C., Haase, D. \& Priess, J. A. Mapping ecosystem services on brownfields in Leipzig, Germany. Ecosyst. Serv. 30, 73-85 (2018).

51. Bai, X. et al. Defining and advancing a systems approach for sustainable cities. Curr. Opin. Environ. Sustain. 23, 69-78 (2016).

52. Ossola, A. \& Niemelä, J. Urban Biodiversity: From Research to Practice. (Routledge, London, 2017).

53. Vogt, J. et al. Citree: a database supporting tree selection for urban areas in temperate climate. Landsc. Urban Plan. 157, 14-25 (2017).

54. Baraldi, R. et al. An integrated study on air mitigation potential of urban vegetation: from a multi-trait approach to modeling. Urban For. Urban Green. 41, 127-138 (2019).

55. Roloff, A., Korn, S. \& Gillner, S. The climate-species-matrix to select tree species for urban habitats considering climate change. Urban For. Urban Green. 8, 295-308 (2009).

56. Barnett, J. \& O'Neill, S. Maladaptation. Glob. Environ. Chang. 2, 211-213 (2010).

57. Kendal, D. et al. A global comparison of the climatic niches of urban and native tree populations. Glob. Ecol. Biogeogr. 27, 629-637 (2018).

58. Díaz, S. et al. Functional traits, the phylogeny of function, and ecosystem service vulnerability. Ecol. Evol. 3, 2958-2975 (2013).

59. Tiwary, A. et al. Development of multi-functional streetscape green infrastructure using a performance index approach. Environ. Pollut. 208, 209-220 (2016).
60. Kabisch, N. \& Haase, D. Green justice or just green? Provision of urban green spaces in Berlin, Germany. Landsc. Urban Plan. 122, 129-139 (2014).

61. Andersson, E. et al. Enabling green and blue infrastructure to improve contributions to human well-being and equity in urban systems. Bioscience 69 566-574 (2019).

62. Frantzeskaki, N. et al. Nature-based solutions for urban climate change adaptation: linking science, policy, and practice communities for evidence-based decision-making. Bioscience 69, 455-466 (2019).

63. Voigt, A., Kabisch, N., Wurster, D., Haase, D. \& Breuste, J. Structural diversity as a key factor for the provision of recreational services in urban parks-a new and straightforward method for assessment. Ambio 43, 480-491 (2014).

64. Cohen-Shacham, E. et al. Core principles for successfully implementing and upscaling nature-based solutions. Environ. Sci. Policy 98, 20-29 (2019).

65. Dushkova, D. \& Haase, D. Not simply green: nature-based solutions as a concept and practical approach for sustainability studies and planning agendas in cities. Land 9, 19 (2020).

66. Hansen, R., Olafsson, A. S., van der Jagt, A. P. N., Rall, E. \& Pauleit, S. Planning multifunctional green infrastructure for compact cities: What is the state of practice? Ecol. Indic. 96, 99-110 (2019).

67. Rall, E., Bieling, C., Zytynska, S. \& Haase, D. Exploring city-wide patterns of cultural ecosystem service perceptions and use. Ecol. Indic. 77, 80-95 (2017).

68. Threlfall, C. G. \& Kendal, D. The distinct ecological and social roles that wild spaces play in urban ecosystems. Urban For. Urban Green. 29, 348-356 (2018).

69. Lavorel, S., McIntyre, S., Landsberg, J. \& Forbes, T. D. A. Plant functional classifications: from general groups to specific groups based on response to disturbance. Trends Ecol. Evol. 12, 474-478 (1997).

70. Harrington, R. et al. Ecosystem services and biodiversity conservation: concepts and a glossary. Biodivers. Conserv. 19, 2773-2790 (2010).

71. Star, S. L. \& Griesemer, J. R. Institutional ecology, translations' and boundary objects: amateurs and professionals in Berkeley's Museum of Vertebrate Zoology, 1907-39. Soc. Stud. Sci. 19, 387-420 (1989).

72. Turnhout, E. The effectiveness of boundary objects: the case of ecological indicators. Sci. Public Policy 36, 403-412 (2009).

\section{ACKNOWLEDGEMENTS}

Erik Andersson's, Dagmar Haase, and Daria Sikorska's research was supported as part of the project ENABLE, funded through the 2015-2016 BiodivERsA COFUND call for research proposals, with the national funders The Swedish Research Council for Environment, Agricultural Sciences, and Spatial Planning, Swedish Environmental Protection Agency, German aeronautics and space research centre, National Science Centre (Poland), The Research Council of Norway and the Spanish Ministry of Economy and Competitiveness. In addition, Erik was supported by the SMARTer Greener Cities project through the Nordforsk Sustainable Urban Development and Smart Cities program. Dagmar benefited from the GreenCityLabHue Project (FKZ 01LE1910A) and the CLEARING HOUSE (Collaborative Learning in Research, Information-sharing and Governance on How Urban forest-based solutions support Sino-European urban futures) Horizon 2020 project (No 1290/2013), as well as the EU Horizon 2020 project CONNECTING Nature - COproductioN with NaturE for City Transitioning, Innovation and Governance (Project Number: 730222). Chiara Cortinovis acknowledges financial support by the Swedish Research Council for Environment, Agricultural Science and Spatial Planning (Formas) project 'Naturebased solutions for urban challenges' (grant n. 2016-00324). Dave Kendal is supported by ARC Linkage Project LP160100439 and the Healthy Future Environments and People REP grant. Timon McPhearson is supported by the US National Science Foundation (NSF grant no. SES 1444755), as well as the US NSF Accel-Net program NATURA (grant no. 1927167), and US NSF Convergence program (grant no. 1934933) and the SMARTer Greener Cities project through the NordForsk Sustainable Urban Development and Smart Cities program. Angela Lausch is Member of the GEO BON-Group on Earth Observations (GEO) and GEOEssential Group-Essential GeoVariables for resource efficiency and environmental management' "GEOEssentials" (ERA-NET-Cofund Grant, Grant Agreement No. 689443). Thilo Wellmann receives a scholarship by the Deutsche Bundesstiftung Umwelt DBU (German Federal Environmental Foundation). Some icons designed by macrovector / Freepik.

\section{AUTHOR CONTRIBUTIONS}

Erik Andersson and Dagmar Haase together developed the idea and led the paper writing. All other authors, listed in alphabetic order, contributed with discussion points and helped edit the text. Thilo Wellmann developed the figures.

\section{COMPETING INTERESTS}

The authors declare no competing interests. 


\section{ADDITIONAL INFORMATION}

Supplementary information Supplementary information is available for this paper at https://doi.org/10.1038/s42949-020-00008-4.

Correspondence and requests for materials should be addressed to E.A.

Reprints and permission information is available at http://www.nature.com/ reprints

Publisher's note Springer Nature remains neutral with regard to jurisdictional claims in published maps and institutional affiliations.
Open Access This article is licensed under a Creative Commons Attribution 4.0 International License, which permits use, sharing, adaptation, distribution and reproduction in any medium or format, as long as you give appropriate credit to the original author(s) and the source, provide a link to the Creative Commons license, and indicate if changes were made. The images or other third party material in this article are included in the article's Creative Commons license, unless indicated otherwise in a credit line to the material. If material is not included in the article's Creative Commons license and your intended use is not permitted by statutory regulation or exceeds the permitted use, you will need to obtain permission directly from the copyright holder. To view a copy of this license, visit http://creativecommons. org/licenses/by/4.0/.

(c) The Author(s) 2021 